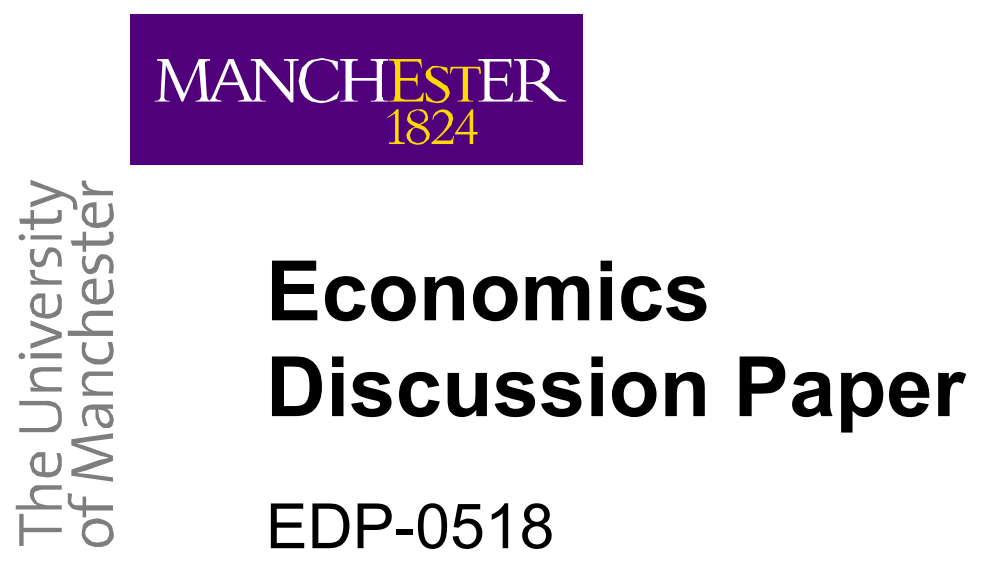

On monopolistic competition and optimal product diversity: a comment on cost structure and workers' rents

by

Pierre M. Picard and Eric Toulemonde

February 2005 


\title{
On monopolistic competition and optimal product diversity: a comment on cost structure and workers' rents*
}

\author{
Pierre M. Picard ${ }^{\dagger}$ \\ University of Manchester and Université catholique de Louvain \\ Eric Toulemonde ${ }^{\ddagger}$ \\ University of Lausanne
}

February 15, 2005

\begin{abstract}
In the Dixit-Stiglitz model of monopolistic competition, entry of firms is socially too small. Other authors have shown that excess entry is also a possibility with other preferences for diversity. We show that the cost structure and workers's rents can also explain excess entry.
\end{abstract}

\section{Introduction}

Do firms offer too many varieties under monopolistic competition? Different strands of economic literature have answered this question. Contributions in industrial organization literature focus on partial equilibrium frameworks. For instance, Chamberlin (1950) considers the case of firms selling perfect

${ }^{*}$ We thank C. d'Aspremont, C. Behrens and Yasusada Murata for helpful comments.

†Université catholique de Louvain, CORE, and University of Manchester, SoSS, Oxford Road, Manchester MP13 9PL, United Kingdom. E-mail: Pierre.Picard@man.ac.uk.

‡DEEP, HEC, Université de Lausanne, BFSH1, CH-1015 Lausanne, Switzerland. Email: eric.toulemonde@unil.ch. 
substitutes and concludes that firms set production to the left of the point of their minimum average cost so that too many firms enter. Dixit and Stiglitz (1977) analyze the case of imperfect substitutes where firms set production levels larger than the (unconstrained) social optimum so that entry is below its social optimum. Generalizing this work, Benassy (1996) and Vives (1999, p.172) show that entry can be too large or too small according to the balance between consumers' preferences for variety and for individual consumption of each single variety. Other contributions have reconsidered Dixit and Stiglitz's (1977) model by allowing firms to behave strategically in a general equilibrium setting. In particular, d'Aspremont et al. (1989), Yang and Heijdra (1993) and d'Aspremont et al. (1996) consider that firms have non zero masses and use their ability to alter price indices and incomes in order to increase their own profits. ${ }^{1}$ In such models, firms' strategic behavior may yield excess entry, which reverses the Dixit and Stiglitz' (1977) result.

In this paper we present a general equilibrium model with imperfect labor markets in which the Dixit and Stiglitz' (1977) prediction can also be reversed. The model includes a sector with constant returns to scale and a sector with increasing returns to scale, allowing workers of the latter to capture a rent (either because these workers are unionized - see McDonald and Solow, 1981 - or because of efficiency wage considerations - see Solow, 1979 and Akerlof and Yellen, 1990). Workers' positive rents raise firms' costs but also inflate the product demand and firms' revenues. The impact of rents on profits and entry then depends on how workers' rents translate to costs and to the demand. If rents are associated to fixed costs activities, they decrease profits on a one-to-one basis. The effect of rents on demand is then dominated by their effect on costs: profits and entry fall with higher rents. By contrast, rents associated to variable costs activities have a smaller impact on profits because firms are able to adapt their production levels. In this case, the effect of rents on demand can dominate their effect on costs: profits rise with higher rents and more firms enter. We thus show that the response of entry to a change in workers' rents depends on the structure of costs. ${ }^{2}$ Furthermore, the equilibrium number of firms can become larger than the social optimum.

\footnotetext{
${ }^{1}$ Such models give evidence of a 'Ford' effect, in reference to Henry Ford who firstly exploited the positive causality between wages and product demand.

${ }^{2}$ To our knowledge, no authors have analyzed the cost side effects on diversity. Gans (1997) develops a model with endogenous fixed costs to capture 'big push' effects, but offers no conclusion about diversity.
} 


\section{The model}

We consider a general equilibrium model under imperfect competition where $m$ individuals consume an homogenous good produced under constant returns to scale and a bundle of differentiated varieties produced under increasing returns to scale. Labor productivity is normalized to one in the production of the former good, which is taken as the numéraire. Individuals share the same preferences: $U=c_{o}^{1-\mu} *\left(\int_{0}^{n} c(i)^{1-1 / \sigma} d i\right)^{\mu \frac{\sigma}{\sigma-1}}$ where $c_{o}$ is the consumption of the numéraire and where $c(i)$ is the consumption of a differentiated variety $i \in[0, n]$. The share of revenue spent on the differentiated varieties is $\mu$ and the share of revenue spent on the numéraire is $1-\mu$; the elasticity of substitution among differentiated varieties is constant and equal to $\sigma>1$. Accordingly, consumers' demand for the differentiated variety $i$ is given by

$$
c(i)=\left(\frac{p(i)}{P}\right)^{-\sigma} \frac{\mu E}{P} \text { where } P \equiv\left(\int_{0}^{n} p(i)^{1-\sigma} d i\right)^{\frac{1}{1-\sigma}}
$$

where $E$ denotes the consumers' expenditure, $p(i)$ is the price of the differentiated variety $i$, and $P$ is the price index of the differentiated varieties.

Individuals work either in the constant returns to scale sector or in the increasing returns to scale sector. In the former sector, we assume unit labor productivity so that the wage is equal to one, i.e. the price of the numéraire. In the latter sector, workers earn a rent which results in higher wages $(w>1)$. As in Picard and Toulemonde (2005a, 2005b), we justify such rents from a bargaining process between employers and employees. Larger wages can also result from incentives to effort as in efficiency models or from workers' investment in industry specific education.

Firm $i$ 's profit can be written as $\pi(i) \equiv[p(i)-v] x(i)-f$ where $v$ and $f$ denote variable and fixed costs respectively. Firms use two inputs: unionized labor and numeraire. The parameters $\alpha$ and $\beta \in[0,1]$ describe the shares of unionized labor in variable and fixed costs so that $v \equiv \alpha w+(1-\alpha)$ and $f \equiv \beta w+(1-\beta)$. Total expenditures in the economy are made of earnings of individuals working in the constant returns to scale sector, and wages of unionized workers ${ }^{3}: E=(m-l)+l w$ where $l$ is the total number of workers paid at the unionized wage $w$.

\footnotetext{
${ }^{3}$ We assume that there is free entry so that profits fall to zero.
} 


\section{Monopolistic competition}

Firm $i$ chooses the price $p(i)$ that maximizes its profits. Under monopolistic competition, each firm takes the index $P$ and the expenditures $E$ as given. Because the product demand is iso-elastic, firm $i$ sets its price as a markup over the variable costs: $p \equiv p(i)=v \sigma /(\sigma-1)$. Given the manufactured price index $\left(P=p n^{-1 /(\sigma-1)}\right)$ and the demand for each variety, output and profits are equal to

$$
x=\frac{(\sigma-1) \mu E}{\sigma v n} \text { and } \pi=\frac{\mu E}{\sigma n}-f
$$

Under free entry, firms enter until their profits fall to zero. Wages may affect profits through their effects on fixed costs, on variable costs, and on expenditures. First, larger wages increase the fixed costs $f$, which clearly reduces the equilibrium number of firms. Second, larger wages increase the variable $\operatorname{costs} v$, but this does not affect $\pi$, as seen in (2). Indeed, with isoelastic demands, an increase in variable costs is automatically matched by a change in the production that leaves profits unaffected. Third, larger wages affect expenditures:

$$
E=m+n(\alpha x+\beta)(w-1)=\frac{\sigma(m-n)(\sigma w+1-\alpha)}{\alpha \sigma(1-\mu)(w-1)+\sigma-\mu}
$$

Whereas larger wages reduce the output (and the employment level) (see (2)), they also raise the earnings of unionized workers so that the net effect on expenditures $E$ is a priori unknown. From the second equality in the above expression, it is readily checked that an increase in wages raises the earnings, which promotes the entry of new firms.

Under free entry, the equilibrium number of firms is given by

$$
n_{e}=\frac{\mu m}{\sigma f(1-\mu)+\mu+\mu(\sigma-1) f / v}
$$

where

$$
\frac{d n_{e}}{d w}>0 \Longleftrightarrow \frac{v \mu(\sigma-1)+v^{2} \sigma(1-\mu)}{\mu(\sigma-1)+v^{2} \sigma(1-\mu)}>f
$$

where we used the definitions of $v$ and $f$ to substitute for $\beta$ and $\alpha$.

The novelty in this paper is the analysis of the effects that wages (costs) have on entry via the expenditures in a general equilibrium framework. Since 
under $w>1, v$ is larger than one, it is readily verified that the left hand side of the last inequality has the following properties: (i) it is larger than one, (ii) it is larger than $f$ if $v>f$ (that is if $\alpha>\beta$ ), and (iii) it increases with $v$ - and thus with $\alpha$ - for reasonable values of union wage premium (i.e. for $w \in[1,1+\sqrt{(\sigma-\mu) /(\sigma(1-\mu))}]$ which includes $w \in[1,2])$.

As a result of property (i), an increase in wages always promotes entry if fixed costs are paid in terms of the numéraire $(f=1$ or $\beta=0)$. As a consequence of property (ii), the increase in wages also promotes entry if the share of unionized labor is proportionally larger in variable costs than in fixed costs. Finally, because of property (iii) and because $f$ increases with $\beta$, the following proposition applies:

Proposition 1 An increase in unionized wages raises the number of varieties if the share of unionized workers in the variable costs $(\alpha)$ is high enough or if their share in the fixed costs $(\beta)$ is low enough.

The natural next question is whether the economy operates with too much or too little entry.

\section{Entry: too much or too little?}

We compare the competitive equilibrium with the (unconstrained) social optimum where a planner is able to choose the values of $c_{o}, c(i)$ and $n$ that maximize utility under the resource constraint. In the constant returns to scale sector, the economy uses $c_{o}$ units of labor (for producing $c_{o}$ ) and $(1-\beta) n+(1-\alpha) \int_{0}^{n} c(i) d i$ units of labor to produce the input for the other sector. The increasing returns to scale sector also uses $\beta n+\alpha \int_{0}^{n} c(i) d i$ units of labor. The resource constraint is therefore $m=c_{o}+\int_{0}^{n} c(i) d i+n$. Substituting $c_{o}$ from the constraint in the planner's objective, maximizing with respect to $c(i)$ and $n$, and using symmetry $(c(i)=c \forall i)$ yields the first best levels of consumption and varieties: $c_{o}=\sigma-1$ and $n_{o}=\mu \mathrm{m} /(\sigma-1+\mu)$. Comparing $n_{e}$ to $n_{o}$ gives

$$
n_{e}-n_{o}<0 \Longleftrightarrow \frac{(\sigma-1) v}{\sigma(1-\mu) v+\mu(\sigma-1)}<f
$$

If unionized workers do not manage to get larger wages than the workers from the constant returns to scale sector $(w=1)$, then $v=f=1$ and the 
above inequality holds. This is the standard result according to which there is too little entry under perfect labor markets (Dixit and Stiglitz, 1977 and Vives, 1999). Now when unionized workers get larger wages, the expenditures $E$ increase with wages, which may promote entry and may result in over provision of varieties, particularly when wages have a strong effect on the number of firms $n_{e}$. Indeed, it can be checked that the left hand side of the condition increases in $v$, and thus in $\alpha$, whereas the right hand side increases with $\beta$. This gives the following proposition

Proposition 2 There is too much entry if the share of unionized workers in the variable costs $(\alpha)$ is high enough or if their share in the fixed costs $(\beta)$ is low enough. Otherwise, there is too little entry.

This proposition readily applies to configurations where variable and fixed costs are made of a single type of workers, i.e. when $\alpha$ and $\beta$ are equal to 0 or 1 . Then, one can check that excess entry is supported only when the variable cost is paid in terms of unionized labor whereas the fixed cost is paid in terms of the numéraire $(\alpha=1, \beta=0)$. Two additional conditions are then required: the share of revenues spent on the differentiated varieties must be large enough $(\sigma \mu>1)$ and unionized wages must be large enough $(w>(\mu \sigma-\mu) /(\mu \sigma-1))$. Because the right hand side of this last condition increases in $\sigma$ and decreases in $\mu$, we conclude that excess entry is more likely when varieties are lower substitutes (low $\sigma$ ) or when they are more intensely consumed (high $\mu$ ). In both cases, firms benefit from both larger market power and larger sales, which increases profits and attracts new firms that may enter in excess. Furthermore, excess entry is not inconsistent with reasonable values of economic parameters. ${ }^{4}$

\section{References}

Akerlof G.A. and Yellen J.L. (1990), The Fair Wage-Effort Hypothesis and Unemployment, Quarterly Journal of Economics, 105, 255-283.

Benassy J.P. (1996), Taste for Variety and Optimum Production Patterns in Monopolistic Competition, Economic Letters, 52, 41-47.

\footnotetext{
${ }^{4}$ These two conditions are fulfilled for instance if $\sigma=4, \mu=0.75$ and $w \geq 1.125$, which are relevant values of parameters (see e.g. Hanson, 1998, Head and Mayer, 2004 for estimations of $\sigma$ and $\mu$, see Lewis, 1986 for estimations of $w$ ).
} 
Chamberlin E. (1950), Product Heterogeneity and Public Policy, American Economic Review Proceedings, 40, 85-92.

d'Aspremont C., Dos Santos Ferreira R., Gerard-Varet L.A., (1989), Unemployment in a Cournot Oligopoly Model with Ford Effects, Recherches Economiques de Louvain. 1989, 55, 33-60.

d'Aspremont C., Dos Santos Ferreira R., Gerard-Varet L.A. (1996), On the Dixit-Stiglitz Model of Monopolistic Competition, American Economic Review, 86, 623-629.

Dixit A.K. and Stiglitz J.E. (1977), Monopolistic Competition and Optimum Product Diversity, American Economic Review, 67, 297-308.

Gans J.S. (1997), Fixed Cost Assumptions in Industrialization Theories, Economic Letters, 56, 111-119.

G.H. Hanson (1998), Market Potential, Increasing Returns, and Geographic Concentration, NBER Working Paper 6429.

K. Head and T. Mayer (2004), The Empirics of Agglomeration and Trade, in Handbook of Urban and Regional Economics, Ed. J.V. Henderson and J-F Thisse.

H. G. Lewis (1986), "Union Relative Wage Effects: A Survey", The University of Chicago Press, Chicago.

McDonald I.M. and Solow R.M. (1981), Wage Bargaining and Employment, American Economic Review, 71, 896-908.

P. Picard and Toulemonde E. (2005a), Unions and Firms Agglomeration, Forthcoming in European Economic Review.

P. Picard and Toulemonde E. (2005b), On monopolistic competition and optimal product diversity: a comment on cost structure and workers' rent, CORE Discussion Paper 2005/16, Université catholique de Louvain.

Solow, R.M. (1979), Another Possible Source of Wage Stickiness, Journal of Macroeconomics, 1, 79-82.

Vives X. (1999), Oligopoly Pricing: Old Ideas And New Tools, MIT Press.

Yang X. and Heijdra B. (1993), Monopolistic Competition and Optimum Product Diversity: Comment, American Economic Review, 83, 295-301. 